\title{
Pre-operative extracranial and intracranial EEG investigation in patients with temporal lobe epilepsy: trends, results and review of pathophysiologic mechanisms
}

\author{
L.F. Quesney*, B. Abou-Khalii**, A. Cole*, \\ and A. Olivier ${ }^{*}$ \\ "Montreal Neurological Institute, Montreal Quebec \\ Canada, ${ }^{*}$ Department of Neurology, University of \\ Michigan, Ann Arbor, Michigan USA.
}

A thorough understanding of the clinical and EEG correlates of complex partial seizures has been achieved over the last decade, mainly as a result of the utilization of long term EEG-video monitoring technique in the pre-operative investigation of patients with focal cerebral seizures who are considered for surgical therapy (1-17). Evidence derived from EEG-video recording of complex partial seizures of temporal lobe origin, suggest that the specificity of classical semiological signs traditionally attributed to the temporal lobe, is rather limited $(12,18,19)$. Some classical ictal symptomatology remains, however, as a reliable predictor of seizure onset in the temporal lobe. Such is the case with auditory, olfactory, and vestibular hallucinations, as well, as with experiental phenomena $(9,18,19,20,21)$. Furthermore, EEG investigation of patients with poorly controlled complex partial seizures of temporal lobe origin with chronically implanted intracerebral electrodes, has permitted a more reliable identification of specific anatomical substrates within the temporal lobe responsible for the genesis of this ictal symptomatology (22).

Complex partial seizures of temporal lobe origin normally do not provide clinical lateralizing clues $(3,10,12,13,18,19)$. Lateralization of seizure onset in temporal lobe epileptic patients remains a cornerstone problem in their pre-operative investigation, particularly if one considers that recording of bitemporal independent interictal epileptiform discharges in patients with complex partial seizures of temporal lobe origin who are surgical candidates, is a common phenomenon, ranging from 12 to $40 \%$ according to different series (13,23-28). Whether the etiopathogenesis of bitemporal independent epileptic foci is due to bitemporal damage $(29,30)$ or due to a mechanism of secondary epileptogenesis (mirror focus) $(25,31,32)$, is a controversial issue and it is not always possible to ascertain despite the utilization of sophisticated long-term EEG monitoring and neuro-imaging techniques. Evidence supporting the existence of an underlying bitemporal pathological damage, as opposed to a primary (lesional related) epileptic focus with secondary epileptogenesis (mirror focus) will be presented and discussed.

Most of the pre-operative lateralizing and localizing problems in patients with complex partial seizures of temporal and frontal lobe origin, can be resolved by means of long-term EEG monitoring with extracranial or intracranial electrodes, (13 and 28 as review articles), a technique which can supply useful evidence deriving from three sources: identification of the clinical seizure pattern, recording of the ictal electrographic seizure onset as well as spread and recording of the interictal epileptic abnormalities.

The current study deals mostly with the effectiveness of long term EEG monitoring with extracranial and intracranial electrodes in the localization of the epileptic focus in temporal lobe epileptic patients presenting with unilateral or bilateral independent epileptic discharge. 


\section{The role of extracranial EEG re- cordings in the pre-operative localization of the epileptic focus}

\section{Material and Methods}

A retrospective analysis of the pre-operative localizing effectiveness of extracranial EEG investigation, was performed in a sample of 41 randomly selected patients with poorly controlled complexpartial seizures, who underwent temporal lobectomy at the MNH between 1984-1985. Patients who required depth electrode $E E G$ investigation were not included in this study.

The patients' mean age was 29 years (range: $12-$ 51 years) and the mean time interval between seizure onset and surgery was 12 years.

All patients underwent serial prolonged EEG studies including sleep activation, using scalp and sphenoidal electrodes. A total of 366 prolonged EEG recordings were performed in this group of patients (mean of 9 recordings per patient). Computer assisted telemetry examination equipped with automatic spike and seizure detection, as well as with a push-button marker for ictal events, (33-37) was performed in 34 of these patients in an attempt to record their habitual seizures.

\section{Results}

Two groups of patients were identified:

I. The first group comprised 24 patients presenting with unilateral temporal lobe interictal epileptic abnormality $(58.5 \%)$. A total of 186 EEG recordings were performed in these patients (mean: 7.7. tracings per patient). Forty-two seizures were recorded in 18 patients of this group (range: $1-8$ seizures per patient).

Focal interictal spiking most commonly involving mesial-basal temporal lobe structures was documented in 15 of these patients and regional spiking involving mesial and dorso-lateral temporal lobe structures, was observed in 9 patients (Table I).

Four patients exhibited generalized spike-andwave activity in addition to the focal or regional epileptic disturbance.

In all patients, a predominant background activity disturbance consisting of slow wave activity in

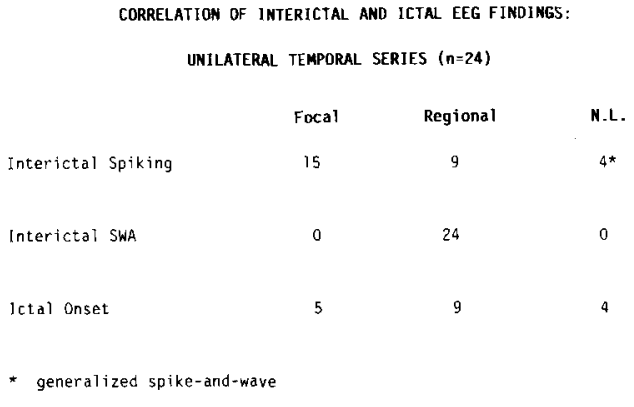

Table 1.

the theta or delta frequency band, was recorded regionally from the temporal lobe exhibiting interictal spiking (Table 1).

Unilateral focal seizure onset involving mesial or dorso-lateral temporal lobe structures was documented in 5 patients (Table 1). Regional seizure onset involving most commonly the temporal, frontal and central regions of one cerebral hemisphere, with consistent predominance of the ictal changes in the temporal lobe, was recorded in 9 patients. In the 4 remaining patients, the initial electrographic changes could not be lateralized. It should be emphasized that in latter group as well as in those patients in whom seizures were not recorded preoperatively ( $n=6)$, localizing evidence deriving from neuro-radiological and neuro-psychological studies was compatible with the localization of the interictal epileptic foci.

In summary, according to these findings, the preoperative localizing effectiveness of ictal recordings obtained with extracranial electrodes in patients with complex partial seizures of temporal lobe origin, presenting with unilateral temporal lobe spiking, can be as high as $77 \%$ (14 out af 18 patients in whom seizures were recorded).

II. The second group comprised 17 patients (mean age: 30 years) presenting with bitemporal independent epileptic foci (41.5\%). A total of 180 EEG recordings were performed in these patients (mean: 10.5 tracings per patient). One hundred and eight seizures were recorded in 16 patients of this group (mean: 6.7 seizures per patient; range: 1-8 seizures per patient).

A correlation between the interictal and ictal findings performed in 16 patients of this group in whom seizures were recorded, was as follows: 10 
CORRELATION OF INTERICTAL AND ICTAL EEG FIMOINGS:

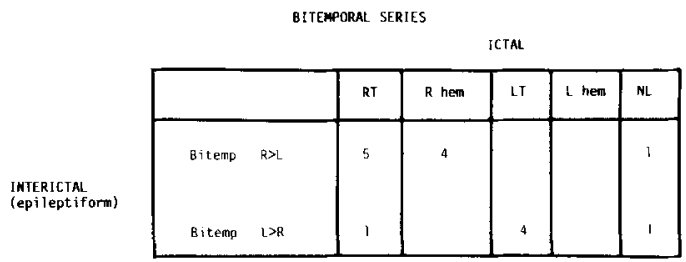

Table 2.

patients exhibited bitemporal independent interictal spiking with consistent right-sided predominance (Table 2). In 9 of these patients, the electrographic seizure onset involved the right temporal lobe or the right hemisphere, with focal accentuation in the temporal region. In the remaining patient, ictal recordings provided no lateralization of the seizure onset. Six patients presented with bitemporal independent epileptic foci with left-sided predominance (Table 2). In 4 of them, the electrographic seizure onset involved the left temporal lobe. In one patient, the seizure onset was lateralized to the right temporal lobe and in the remaining patient, several ictal recordings provided no lateralization of the seizure onset.

In summary, the effectiveness of long-term EEG monitoring with extracranial electrodes in patients with temporal lobe seizures presenting with bitemporal independent epileptic foci, yielded a positive correlation of the side of seizure onset with the anatomical site of predominant interictal epileptic abnormality in 13 out of 16 patients $(81 \%)$. Ictal recordings provided no useful lateralizing information in 2 out of 16 patients $(12.5 \%)$. Only in one patient $(6.5 \%)$, the location of seizure onset was opposite

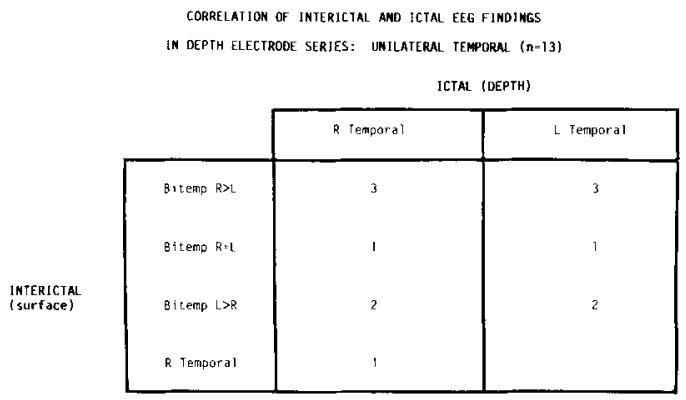

Table 3. to the anatomical site of maximum interictal epileptic abnormality. In these patients, as well as in the two cases in whom the ictal recordings provided no lateralizing evidence of seizure onset, the decision to remove one temporal lobe was supported by neuro-radiological confirmation of a lesion and by neuro-psychological documentation of a lateralized temporal lobe malfunction.

\section{The role of intracerebral EEG re- cordings in the pre-operative local- ization of the epileptic focus}

\section{Material and Methods}

The localizing effectiveness of depth electrode EEG investigation in temporal lobe epilepsy was studied in a population of 18 patients ( 12 females and 6 males) with medically intractable complex partial seizures of temporal lobe origin (mean age: 29 years). This group represents only a sample of the depth electrode investigations performed at the Montreal Neurological Institute, which has been personally studied by the author. Long-term EEG monitoring with extracranial electrodes including sphenoidal leads, revealed bitemporal independent interictal epileptic foci in 17 of these patients and ictal recordings obtained with extracranial electrodes, failed to provide reliable seizure onset lateralization. Chronic stereotactic implantation of depth electrodes in both temporal lobes, was performed by one of us (A.O.) in all 18 patients. Each depth electrode contained 10 contacts, $5 \mathrm{~mm}$ apart. The deepest contacts of the depth electrode were located in the amygdala and hippocampus respectively. The superficial depth electrode contacts sampled EEG activity from the temporal neocortex. Bifrontal depth electrodes were implanted in 17 of these patients. The intracerebral EEG was recorded around the clock for 2-4 weeks (12).

The localizing effectiveness of ictal recording obtained with depth electrodes was assessed in 261 temporal lobe seizures recorded in 18 patients (mean: 14.5 seizures per patient; range: $4-47$ seizures per patient).

Electrographic seizures without clinical behavioral manifestations and seizures in which the EEG onset was missed were not included in this study. 


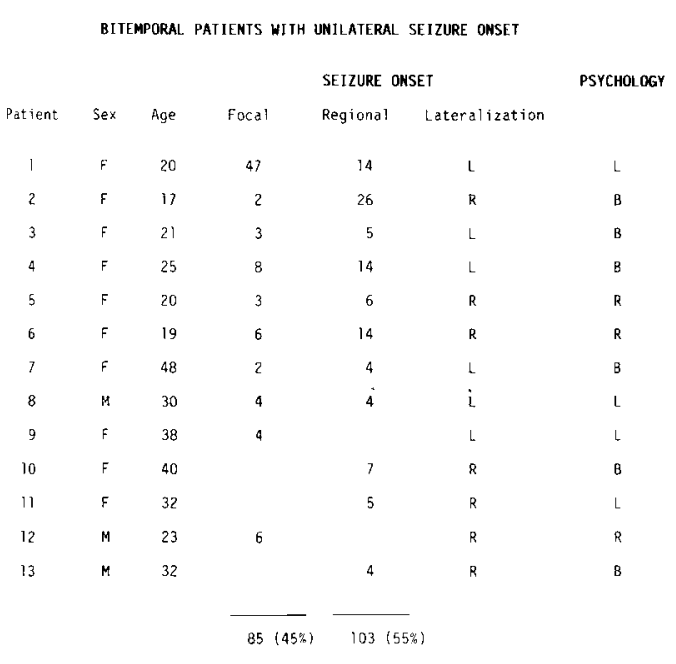

Table 4.

\section{Results}

Two groups of patients were identified:

I. The first group comprised 13 patients $(72 \%)$, with clinical seizures exhibiting electrographic onset in one temporal lobe. Their mean age was 28 years. As illustrated in Table 3, the pre-implantation EEG investigation with extracranial electrodes revealed bitemporal interictal epileptic foci in 12 of these patients ( $\mathrm{R}>\mathrm{L}: 6 ; \mathrm{R}=\mathrm{L}: 2 ; \mathrm{L}>\mathrm{R}: 4)$. In the remaining patient, interictal epileptic abnormality was recorded from the right temporal lobe, but the seizures recorded with extracranial electrodes exhibited a left temporal lobe onset.

In $8 / 13$ patients investigated with dept electrodes, their habitual seizures exhibited an unilateral focal or regional temporal lobe onset.

Focal eletrographic seizure onset (13) involving amygdala or hippocampus was documented in 85 seizures $(45 \%)$ recorded in 10 patients (Table 4 , Figs 1 \& 2). 103 seizures recorded in 11 patients exhibited a regional (13) electrographic $(55 \%)$ onset, most frequently involving the amygdala and hippocampus simultaneously (Fig. 3). In 6 of the patients with unilateral temporal lobe onset as documented by depth electrode recordings, the result of the neuro-psychological examination revealed a bilateral temporal lobe malfunction (Table 4).

In the remaining 5 patients of this group, the recorded seizures showed a focal $(n=2)$ or regional onset $(n=3)$. Two thirds of the seizures disclosing a regional onset involved the amygdala and hippocampus. In one third of the seizures exhibiting regional onset, the temporal neocortex was also involved. Only in $50 \%$ of patients disclosing bitemporal independent epileptic foci with unilateral predominance $(n=10)$, the lateralization of seizure onset as judged by depth electrode recording, was concordant with the side exhibiting predominance of the interictal epileptic abnormality (Table 3).

II. The second group comprised 5 patients $(28 \%)$, in whom the results of depth electrode EEG investigation revealed that their habitual seizures originated on either temporal lobe independently (Table 5 ). Their mean age was 35 years. The nature of the ictal behavioral manifestations did not permit ictal reliable lateralization of seizure onset on clinical grounds.

Table 5 summarizes the localization of seizure onset on either temporal lobe for each individual patient. In three of these patients (\#1,\#2,\#5, Table 5) complex partial seizures with a focal EEG onset were recorded from either temporal lobe independently. In 2 patients of this group (\# 2 and \# 4) a definite unilateral predominance of seizure onset was noticed.

Three of the 5 patients exhibiting bitemporal independent seizures according to depth electrode investigation, also disclosed bitemporal malfunction on neuropsychological testing. These patients could probably be considered as representative samples of bitemporal damage or malfunction associated with bitemporal independent epileptogenesis.

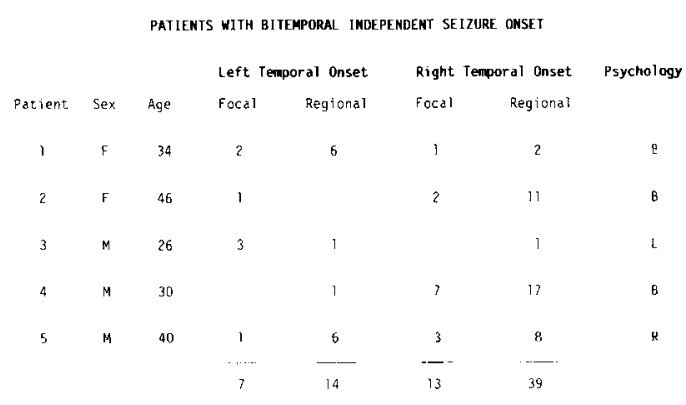

Table 5. 


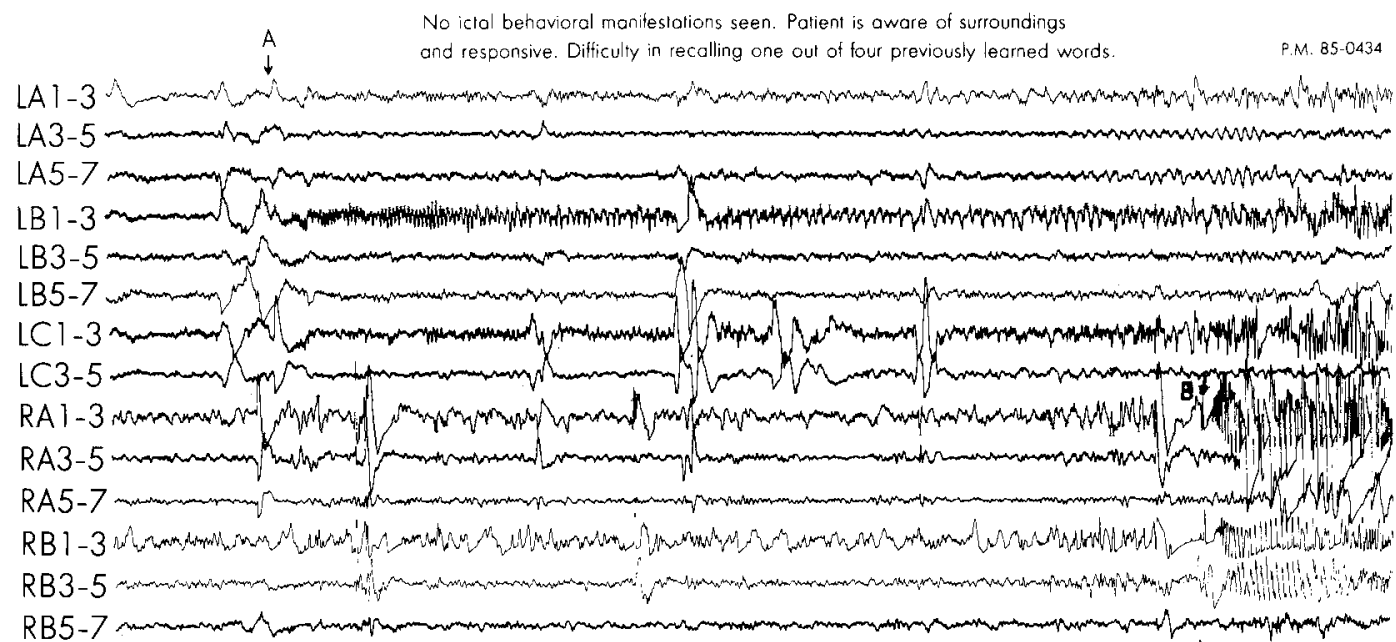

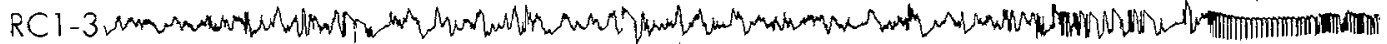
RC3-5

Cont.

still responsive

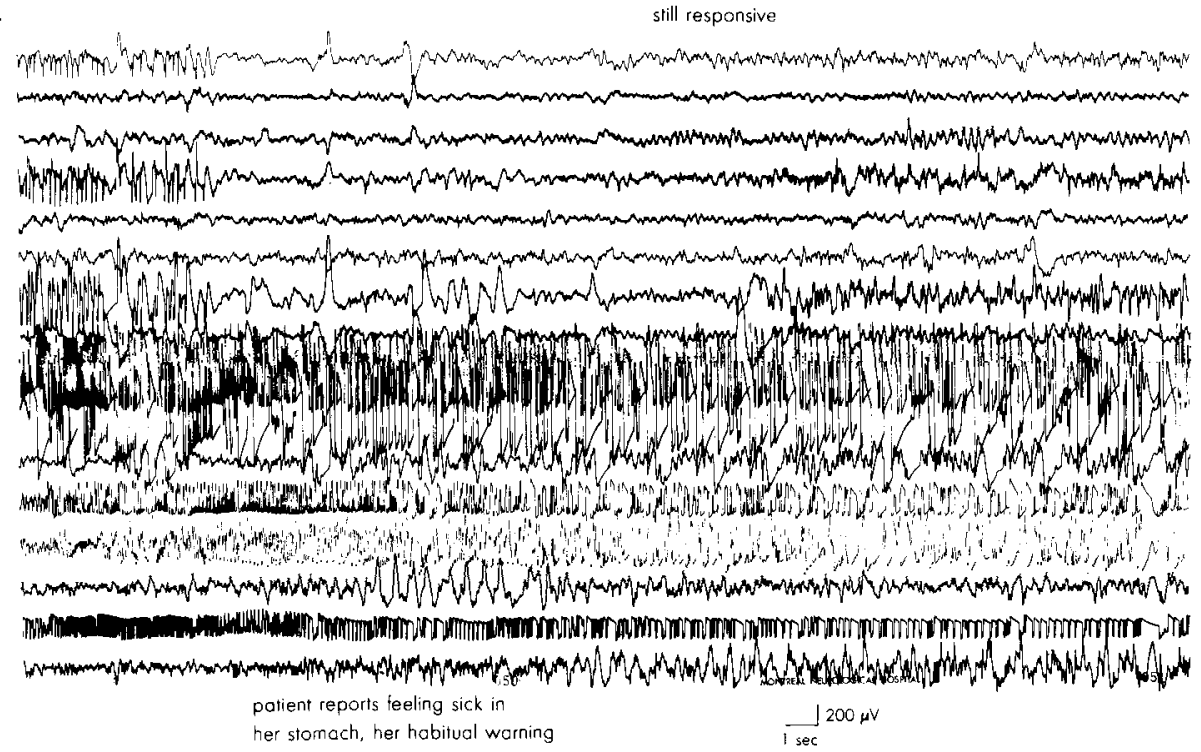

Fig. 1. Arrow at (A): Focal EEG seizure at 10-12 Hz involving the left hippocampus (LB1-3, LC1-3). Arrow at (B): Seizure spread to amygdaloid and hippocampal structures of the right temporal lobe. Between (A) and (B) the patient was aware of surroundings and responsive, but did not recall one out of four previously learned words. Patient reported experiencing her habitual warning after arrest of seizure activity in the left temporal lobe. (L.F. Quesney, 1986, with permission). 


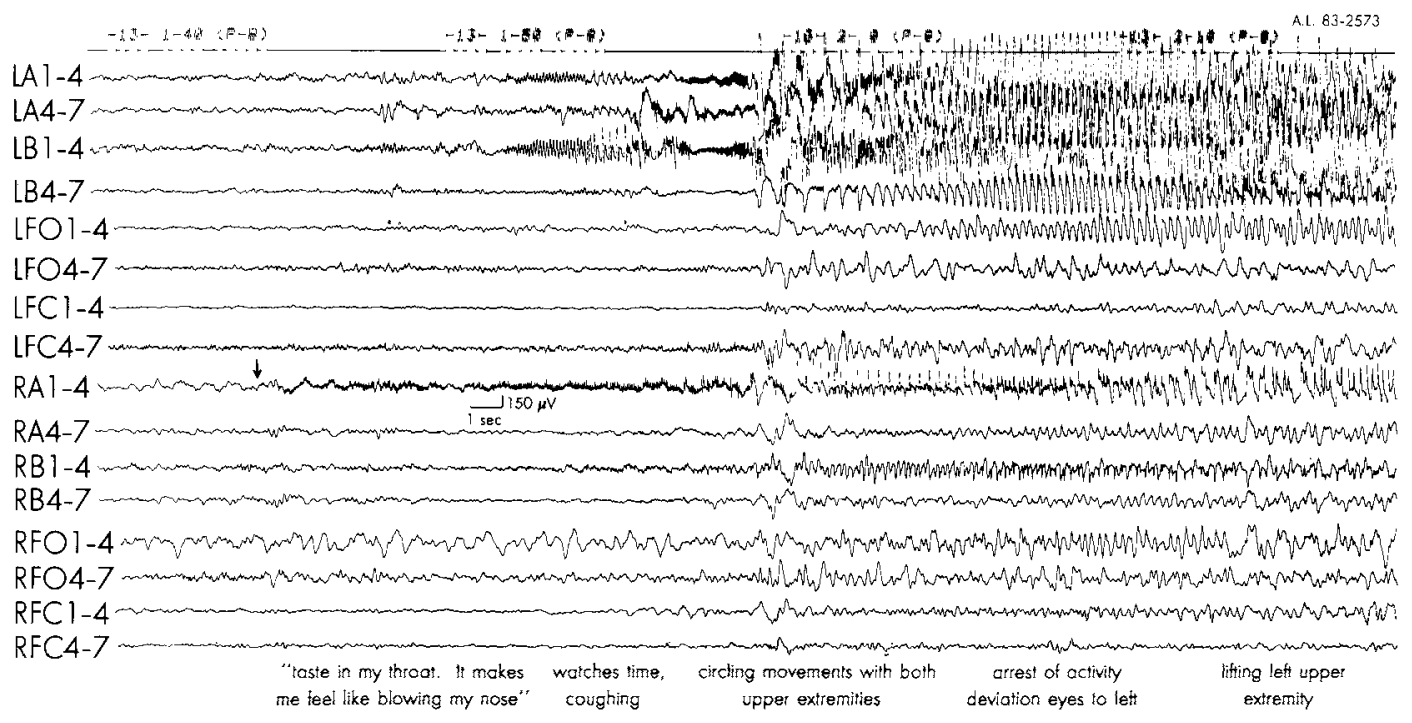

Fig. 2. Focal EEG seizure onset consisting of rhythmic polyspike activity at $18 \mathrm{~Hz}$ recorded from the right amygdala (RA1-4, see arrow), which was associated with a gustatory warning. Seizure spread to amygdaloid and hippocampal regions of the left temporal lobe occurred a few seconds after onset (LA1-4, LA4-7, and LB1-4). Notice that automatic behaviour and arrest of activity were observed during ictal electrographic involvement of both temporal and frontal lobes (FO, orbito-frontal; FC, fronto-cingular). Towards the end of the seizure section illustrated, lifting of the left upper extremity was observed. (L.F. Quesney, 1986, with permission).

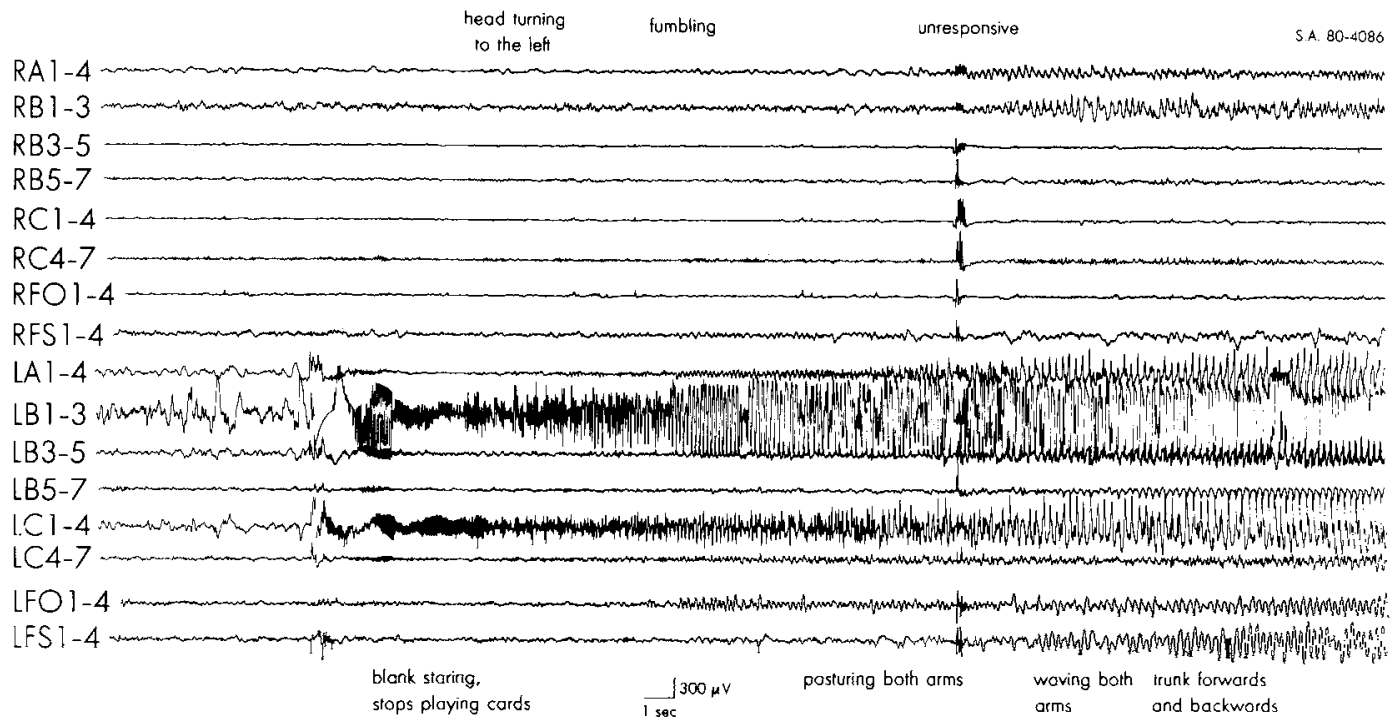

Fig. 3. Focal EEG seizure onset consisting of high-amplitude, rhythmic polyspike activity at $16-18 \mathrm{~Hz}$ recorded from the left hippocampus (LB1-3, LC1-4). Motionless stare was observed shortly after seizure onset. Ipsilateral head turning and automatic behaviour (fumbling) was noticed during electrographic seizure activity restricted to the left temporal lobe. Posturing of both upper extremities was observed following seizure spread to the left orbitofrontal region (LFO1-4) and coinciding with seizure spread to the right temporal lobe (RA14, RB1-3). Patient became unresponsible. Subsequently further automatic behaviour was noticed.

(L.F. Quesney, 1986, with permission). 


\section{Discussion}

The results og this study emphasize the effectiveness of long-term EEG monitoring with extracranial electrodes in the pre-operative localization of epileptic foci in temporal lobe epilepsy. This task is, however, not always possible and admittedly, some patients do require pre-operative EEG investigation with intracranial electrodes $(13,14,38-45,46-$ 48) particularly when the extracranial EEG localization is discordant with the localization evidence derived from ancillary disciplines such as neuropsychology, neuro-radiology and neuro-imaging techniques.

According to different series, bitemporal independent epileptic foci are recorded in $9-40 \%$ of patients with complex partial seizures of temporal lobe origin. The view implying that the genesis of bitemporal independent epileptic foci is due to secondary epileptogenesis is not universally accepted since, many of the etiological factors responsible for focal cerebral seizures such as trauma, anoxia, encephalitis and vasculitis may produce bilateral brain damage. Hippocampal sclerosis, the most common etio-pathological entity of temporal lobe epilepsy, may occur bilaterally in approximately $80 \%$ of temporal lobe epileptic patients according to autopsy studies $(29,30,49,50)$.

The results of this study, suggest a continuum distribution of temporal lobe epilepsy in man. One extreme of this continuum comprises patients with unilateral temporal lobe epilepsy without secondary epileptogenesis, as documented in 24 patients who underwent pre-operative EEG investigation with extracranical electrodes (Table 1). The opposite extreme is represented by patients with bitemporal independent epileptogenesis judged by interictal and ictal recordings obtained with chronically implanted intracerebral electrodes, associated with bitemporal psychological malfunction, a condition

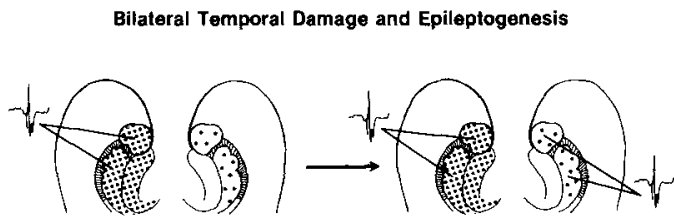

Fig. 4.

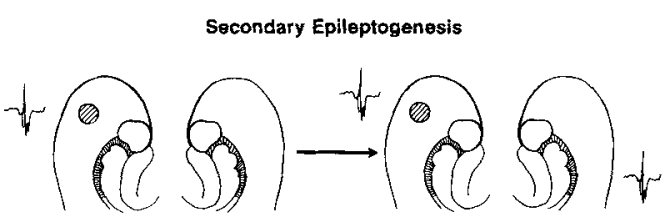

Fig. 5.

which is presumably due to a bitemporal damage or malfunction (Fig. 4). This was the case in at least 3 of the 5 patients investigated with chronically implanted depth electrodes. A large proportion of patients with complex partial seizures of temporal lobe origin, which are surgical candidates, can be grouped in a vast zone between these two extremes. They do not, however, represent a uniform group. Two different population of patients can be identified namely those with unilateral temporal lobe damage or malfunction and interictal evidence for secondary epileptogenesis, as documented in $17 \mathrm{pa}$ tients submitted to pre-operative extracranial EEG investigation (Table 1) and in 7 of the 13 depth electrode patients with strictly unilateral temporal lobe seizures (Table 4). In these patients, the lateralizing evidence deriving from neuropsychological investigation ( $n=7$ patients), was also unilateral and concordant with the side of seizure onset. This population of patients probably represents a pure culture of a primary or lesion-related epileptic focus with secondary epileptogenesis (Fig. 5) (mirror focus) as reported elsewhere $(31,32,25)$. The second group comprises patients in whom depth electrode EEG investigation provided evidence for a bitemporal interictal epileptogenesis and bilateral temporal malfunction on neuro-psychological testing, but in whom the clinical seizures originated only in one temporal lobe. This occurred in 6 of the 13 patients investigated with depth electrodes reported in this series (Table 4). One could postulate the existence of an underlying bitemporal pathological damage in these patients, in order to explain the presence of bitemporal epileptic foci and the bilateral neuropsychological malfunction. The presumptive bitemporal damage would be "supra-liminal" for the elicitation of bitemporal independent interictal epileptic foci and for the production of bitemporal psychological malfunction. It would be however "infra-liminal" in regard to ictal epileptogenesis in one of the temporal lobes. 
Differentiation between the latter two groups based merely on electroencephalographic techniques is not always possible. The lateralizing information deriving from neuro-psychological testing is, however, most valuable (52) and it is possible that the diagnostic efficacy on newly developed neuro-imaging techniques, such as MRI, SPECT and PET scan, might be useful in the "invivo" demonstration of a bilateral temporal lobe damage or metabolic malfunction (53). Post-operative follow-up study will, of course, provide crucial information regarding the significance of bitemporal independent epileptogenesis in terms of seizure control, in patients of this series submitted to temporal lobectomy.

\section{References}

1. Ajmone Marsan C, Goldhammer L. Clinical ictal patterns and electrographic data in cases of partial seizures of frontalcentral-parietal origin. In: MAB Brazier Epilepsy, its Phenomena in Man. New York: Academic Press 1973:235-258.

2. Bancaud J, Talairach J, Bonis A, Schaub G, Szikla G, Morel $P$, Bordas-Ferrer M. La stéréo-électroencéphalographic dans l'Epilepsie. Informations Neurophysiopathologiques Apportées par l'Investigation Fonctionnelle Stéréotaxique. Paris: Masson 1965:321 pp.

3. Bossi L, Munari C, Stoffels C, Bonis A, Bacia T, Talairach J, Bancaud J. Somatomotor manifestations in temporal lobe seizures. Epilepsia 1984:25:70-76.

4. Crandall PH, Walter RD, Rand RW. Clinical applications of studies on stereotactically impianted electrodes in temporallobe epilepsy. J Neurosurg 1963:20:827-840.

5. Daly D. Ictal manifestations of complex partial seizures. In: IK Penry, DD Daly eds. Advances in Neurology, Vol. 11. Complex Partial Seizures and their Treatment. New York: Raven Press 1975:57-83.

6. Delgado-Escueta AV, Nashold B, Freedman M, Keplinger C, Waddell G, Miller P, Carwille S. Videotaping epileptic attacks during stereoencephalography. Neurology 1979:29:473-489.

7. Engel Jr. J. A practical guide for routine EEG studies in epilepsy. J clin Neurophysiol 1984: 1:109-142.

8. Gastaut H, Vigouroux M. Electro-clinical correlations in 500 cases of psychomotor seizures. In: M. Baldwin and P. Bailey eds. Temporal Lobe Epilepsy. Springfield; Charles C. Thomas: 1967:118-128.

9. Gloor P, Olivier A, Quesney LF, Andermann F, Horowitz S. The role of the limbic system in experimental phenomena of temporal lobe epilepsy. Ann Neurol 1982:12:129-144.

10. Ochs R, Gloor P, Quesney F, Ives J, Olivier A. Does headturning during a seizure have lateralizing or localizing significance? Neurology 1984:34:884-890.
11. Porter R, Penry JK, Wolf Jr. AA. Simultaneous documentation of clinical and electroencephlographic manifestations of epileptic seizures. In: P. Kellaway I. Petersén eds. Quantitative Analytic Studies in Epilepsy. New York: Raven Press 1976:253-268.

12. Quesney LF. Clinical and EEG Features of Complex Partial Seizures of Temporal Lobe Origin. Epilepsia 1986:27:Suppl. 2:S27-S45.

13. Quesney LF, Gloor P. Localization of Epileptic Foci. Longterm Monitoring in Epilepsy (EEG Suppl. No 37) J. Gotman JR Ives, P. Gloor eds. Elsevier Science Publishers B.V. 1985

14. Williamson PD, Spencer DD, Spencer SS, Mattson RH. Presurgical intensive monitoring using depth electroencephalography in temporal lobe epilepsy. In: JA Wada, JK Penry eds. Advances in Epileptology, Xth Epilepsy Int. Symp. New York, Raven Press: 1980:73-81.

15. Robillard A, Saint-Hilaire JM, Mercier M. Bouvier G. The laterilization and Localizing Value of Adversion in Epileptic Seizures. Neurology 1983:33:1241-1242.

16. Walsh GO, Delgado-Escueta AV. Type II Complex Partial Seizures: Poor Results of Anterior Temporal Lobectomy. Neurology 1984:34:1-13.

17. Wieser HG. Electroclinical Features of the Psychomotor Seizure. Stuttgart and London: Butterworths: 1983b.

18. Williamson PD, Wieser HG, Delgado-Escueta AV. Clinical Characteristics of Partial Seizures. In: J. Engel, Jr. ed. Surgical Treatment of the Epilepsies, New York: Raven Press 1987:101-120.

19. Ajmone-Marsan C. Commentary: Clinical Characteristics of Partial Seizures. In: J. Engel Jr. ed. Surgical Treatment of the Epilepsies, New York: Raven Press, 1987:121-127.

20. Halgren E, Walter RD, Cherlow DG, Crandall PH. Mental Phenomena Evoked by Electrical Stimulation of the Human Hippocampal Formation and Amygdala. Brain 1978: 101:83117.

21. Weingarten SM, Cherlow DG, Halgren E. The Relationship of Hallucinations to the Depth Structures of the Temporal Lobe. In: Sweet WH, Obrador S, Martin-Rodriguez JG, eds. Neurosurgical Treatment in Psychiatry and Pain and Epilepsy. Baltimore: University Park Press: 1976:553-568.

22. Commission on Classification and Terminology of the International League Against Epilepsy. Proposal for Classification of Epilepsies and Epileptic Syndromes. Epilepsia 1985:26:268-278.

23. Bloom D, Jasper H. Rasmussen T. Surgical therapy in patients with temporal lobe seizures and bilateral EEG abnormality. Epilepsia:1959/60:1:351-365.

24. Falconer MA, Serafetinides EA. A follow-up study of surgery in temporal lobe epilepsy. J Neurol Neurosurg Psychiat 1963:26:154-165.

25. Bancaud J, Talairach J, Bonis A, Bernoulli C, Bordas-Ferrer M. Constitution chez l'homme des foyers épiletgogénes secondaires. Rev Neurol 1969:121:297-306.

26. Engel J Jr, Driver MV, Falconer MA. Electrophysiological correlates of pathology and surgical results in temporal lobe epilepsy. Brain 1975:98:129-156.

27. Rasmussen $\mathbf{T}$. Surgical treatment of patients with complex partial seizures. In: JK Penry and DD Daly eds. Complex Partial Seizures and their Treatment, Advances in Neurology, Vol. 11. New York: Raven Press, 1975:415-449. 
28. Quesney LF. Extracranial EEG Evaluation. In: J. Engel Jr. ed. Surgical Treatment of the Epilepsies. New York: Raven Press. 129-171.

29. Margerison JH, Corsellis JAN. Epilepsy and the Temporal Lobes. Brain 1966:89:499-530.

30. Sano K, Malamud N, Clinical Significance of Sclerosis of the Cornu Ammonis. Arch Neurol Psychiatry 1953: 70:40-53.

31. Morrell F. Secondary epileptogenic lesion. Epilepsia 1959/ 60:1:538-560.

32. Morrell F. Secondary Epileptogenesis in Man. Arch neurol 1985:42:318-335.

33. Gotman J. Automatic Recognition of Epileptic Seizures in the EEG. Electroenceph clin Neurophysiol 1982:54:530540.

34. Gotman J, Gloor P. Automatic recognition and quantification of interictal epileptic activity in the human scalp EEG. Electroenceph Clin Neurophysiol 1976:4:513-529.

35. Ives JR, Gloor P. A long-term-lapse video system to document the patients spontaneous clinical seizure synchronized with the EEG. Electroeceph clin Neurophysiol 1978:45:412416.

36. Ives JR, Thompson CJ, Gloor P, Olivier A, Woods JF. The on-line detection and via a radio telemetry link. Electroenceph clin Neurophysiol 1974:37-205.

37. Ives JR, Thompson CJ, Gloor P. Seizure monitoring a new tool in electroencephalography. Electroenceph clin Neurophysiol 1976:41:422-427.

38. Gloor P. Electroencephalography and the role of intracerebral depth electrode recordings in the selection of patients for surgical treatment of epilepsy. In: RJ Porter, RH Mattson, AA Ward, M Dam eds. Advances in Epileptology. XVth Epilepsy Int. Symp. New York: Raven Press, 1984:433-437.

39. Gloor P. Olinier A, Ives J. Prolonged seizure monitoring with stereotaxically implanted depth electrodes in patients with bilateral interictal temporal epileptic foci: how bilateral is bitemporal epilepsy? In: JA Wada, JK Penry eds. Advances in Epileptology. Xth Epilepsy Int. Symp. New York:Raven Press, 1980:83-88.

40. Lesser RP, Dinner DS, Lueders H, Morris HH. Differential diagnosis and treatment of intractable seizures. Cleve Clin Quart 1984:51:227-240.

41. Lueders H, Hahn J, Lesser RP, Dinner DS, Rothner D, Erenberg $\mathrm{G}$. Localization of epileptogenic spike foci: comparative study of closely spaced scalp electrodes, nasopharyngeal, sphenoidal, subdural and depth electrodes. In: H. Akimoto H. Kazamatsuri M. Seino AA. Ward eds. Advances in Epileptology. XIIIth Epilepsy Int. Symp. New York:Raven Press, 1982:185-189.

42. Olivier A, Gloor P, Quesney LF, Andermann F. The indications for and the role of depth electrode recording in epilepsy. Appl Neurphysiol 1983:46:33-36.

43. Wyler AR, Ojemann GA, Lettich, E Ward Jr, AA. Subdural strip electrodes for localizing epileptogenic foci. J Neurosurg 1984:60:1195-1200.
44. Spencer SS. Depth electroencephalography in selection of refractory epilepsy for surgery. Ann Neurol 1981:9:207-214.

45. Spencer SS, Spencer DD, Williamson PD, Mattson RH. The localizing value of depth electroencephalography in $32 \mathrm{pa}-$ tients with refractory epilepsy. Ann Neurol 1982:12:248253.

46. Ojemann GA, Engel J, Jr. Acute and Chronic Intracranical Recording and Stimulation. In:J Engel Jr ed. Surgical Treatment of the Epilepsies. New York: Raven Press, 1987:263288.

47. Bancaud J. Chauvel P. Commentary: Acute and Chronic Intracranical Recording and Stimulation with Depth Electrodes. In:J Engel Jr ed. Surgical Treatment of the Epilepsies. New York: Raven Press. 1987:289-296.

48. Luders H, Lesser RP, Dinner DS, Morris HH, Hahn JF, Friedman L, Skipper G, Wyllie E, Friedman D. Commentary: Chronic Intracranial Recording and Stimulation with Subdural Electrodes. In:J Engel Jr ed. Surgical Treatment of the Epilepsies. New York:Raven Press. 1987:297321.

49. Mouritzen-Dam A. Hippocampal neuron loss in epilepsy and after experimental seizures. Acta Neurol Scand 1982:66:601-642.

50. Babb TL, Brown WJ. Pathological Findings in Epilepsy. In:J Engel Jr ed. Surgical Treatment of the Epilepsies. New York:Raven Press, 1987:511-540.

51. Morrell F, Wada J, Engel J Jr. Appendix III: Potential Relevance of Kindlking and Secondary Epileptogenesis to the Consideration of Surgical Treatment for Epilepsy.

52. Milner B. Psychological aspects of focal epilepsy and its neurosurgical management. In: DP Purpura, JK Penry, RD Walter eds. Neurosurgical Management of the Epilepsies. Advances in Neurology, Vol. 8. New York: Raven Press. 1975:299-332.

53. Sperling MR, Sutherling WW, Nuwer MR. New Techniques for Evaluating Patients for Epilepsy Surgery. In: J Engel Jr ed. Surgical Treatment of the Epilepsies. New York: Raven Press. 1987:235-257.

\section{Address:}

Dr. L.F. Quesney

*Montreal Neurological Institute

3801 University

Montreal, Que. H3A 2B4

Canada.

**Department of Neurology

University of Michigan

Medical Center

1500 E. Medical Center Drive

Ann Arbor, Mi 48109-0036

U.S.A. 